\title{
Learned Societies and Co-operation in Research
}

$\mathrm{D}^{\mathrm{n}}$ R. R. E. MORTIMER WHEELER showed no little wisdom in his selection of a subject for his presidential address to the Conference of Delegates of Corresponding Societies at the Leicester meeting of the British Association. The position of the learned society in relation to the present tendency towards the centralisation and co-ordination of scientific research is becoming increasingly difficult. This applies more particularly to the local learned society of the older type, in which the amateur naturalist or archæologist once flourished. In London and the larger provincial cities, more especially if these happen to be university centres, a professional element helps to direct the activities of the society and to keep it in touch with scientific movement. Dr. Wheeler, however, evidently had in mind the smaller society of the provinces, which has done valuable work in the past, but at the present day is in danger of losing that enthusiastic support, which as the British Association has reason to know, was a valuable adjunct in securing the conservation of local antiquities or other material of scientific interest or importance, as well as in local scientific observation and record.

In urging the co-operation of local scientific societies in the promotion of scientific research by assisting in the work of centralisation and delegation, Dr. Wheeler drew his arguments in the main from his own subject of archæology. He indicated how by such co-operation the societies would assist in the avoidance of wasted effort and overlapping, and referred more particularly to the scheme which Sir Charles Peers, as president of the Society of Antiquaries, had drawn up, after consultation with local archæological societies, for a considered policy of research. Dr. Wheeler pointed out that the local societies of a generation or two ago promoted a great deal of research, varying widely in value, which, if it did not create a scientific understanding of archæology, established a widespread sympathy and understanding of that study. He went on to say, however, that the growth of professionalism in archæology, made necessary by the requirements of scientific technique, is bringing about an ever-widening rift between the professional and the layman, which is endangering the sympathy and help of the lattermore necessary in this branch of knowledge than in any other.

As a first step towards the re-establishment of sympathy between professional and layman, Dr. Wheeler deprecated the use of an obscure and pretentious technical terminology, which in archæology is noticeably becoming a jargon, in favour of a language intelligible to the general public-a discipline for the scientific worker which would compel a constant simplification and valuation of ideas. Secondly, he urged greater co-operation and more frequent opportunities of meeting between the learned societies of metropolitan centres and local learned societies. Co-operation in drawing up and carrying out schemes of organised scientific research was indicated as a possibility. In this connexion, in amplification of the term 'useful' as applied to such co-ordinated research, he referred to the work of the South-Eastern Union of Scientific Societies in ascertaining the distribution of a certain species of anopheline mosquito, which helped to counter the danger of a spread of malaria in England after the War. With this as an example, Dr. Wheeler emphasised the advantage to be gained from regional congresses or unions of scientific bodies as machinery for stimulating and co-ordinating effort, and referred to the steps which are being taken to form such a union for the midland area of England.

\section{Plastics and their Genesis}

TN a lecture delivered by Prof. G. T. Morgan at 1 the Plastics Industrial Exhibition at the Science Museum, South Kensington, on July 19 and printed in Chemistry and Industry of Aug. 18, reference was made particularly to numerous intermediates of which formaldehyde, urea, thiourea and the tar acids are notable examples, since these enter into the composition of various typical artificial resins. These products have received particular attention at the Chemical Research Laboratory, Teddington.

Formaldehyde is manufactured by dehydrogenating methyl alcohol in presence of a catalyst such as copper or platinum, the former metal being preferred industrially. Methyl alcohol is derived either by fractionation from crude wood spirit obtained in wood distillation, or from high pressure synthesis. The latter process, which is especially serviceable in countries where coal is more plentiful than wood, is based on the condensation which occurs between carbon monoxide ( 1 vol.) and hydrogen ( 2 vols.) when this gaseous mixture is circulated at $450^{\circ}$ and under a pressure of 200 atmospheres over a catalyst such as basic zinc chromate, which becomes reduced to zinc chromite. The main product (about 99 per cent) is methyl alcohol (methanol), but small amounts of higher primary alcohols (propyl and butyl) are also formed. Formaldehyde itself is a gas which dissolves readily in water so that it generally occurs in commerce as the 40 per cent aqueous solution known as formalin. It also oceurs as polymerised paraformaldehyde and as its condensation product with ammonia, when it yields a colourless crystalline compound, $\left(\mathrm{CH}_{2}\right)_{8} \mathrm{~N}_{4}$, known as hexamethylenetetramine, hexamine, hexa or H.M.T.

Enormous quantities of urea are now produced by high pressure processes from carbon dioxide and synthetic ammonia. Thiourea is made by heating ammonium isothiocyanate at $140^{\circ}$, when a molecular rearrangement occurs recalling Wöhler's original synthesis of urea in 1828. By acting on either urea or thiourea alone, or a mixture of the two, with formaldehyde in presence of an alkali, syrups are obtained which are of the heat convertible resin class, so that they can yield moulded articles when mixed with paper pulp and heated under pressure. The glyptal resins are usually derived from glycerol and phthalic anhydride, and several procedures were mentioned whereby modifications can be effected in this group of plastics.

The phenol-formaldehyde resins are based on the pioneering work of L. H. Baekeland (1908). A resin 
of the bakelite type may be produced from a fraction of low temperature tar boiling at $180^{\circ}-200^{\circ}$ and the appropriate amount of formalin heated in the presence of the triethylamine as catalyst. The mixture speedily resolves itself into three layers, a supernatant layer containing neutral tar oils, a middle aqueous layer representing the water originally present in the formalin, and a bottom layer of crude resin. In practice this product may be purified either by solvent extraction or by steam distillation under reduced pressure. In this process, where the tar acids have not been isolated by the usual successive treatment with an alkali and acid, the main products are bakelite resin, a resin of the Novolak type extractible with organic solvents and used for spirit varnishes, and the neutral tar oils. In spite of the mixed character of the phenols, the resulting bakelite resins have been shown to have quite satisfactory electrical and physical properties.

In addition to monohydric phenols immediately derivable from coal tar, resorcinol and the naphthols have been suggested as resin components, especially for gramophone records. During the last three years, suggestive experiments have been made on condensations between formaldehyde and acetone. One, two, four or seven molecular proportions of aldehyde react with acetone and some three intermediates are obtained which have the property of resinification. The resulting resins are colourless and transparent; they may be either hard and vitreous or elastic, depending on the experimental conditions. Resins of the non-heat convertible type are obtainable by condensing formaldehyde with various aromatic hydrocarbons such as toluene and naphthaline.

Formaldehyde interacts very readily with aromatic amines even in aqueous solution or suspension. Such condensation products have recently been employed as intermediates in the production of resins for laminated board, having good electrical properties.

Attention was also directed to the increasingly important class of polymerisation resins. One of the most suggestive of this type, based on vinyl acetate, has been recommended for use in moulding, panelling and as a substitute for glass. Reference was also made to the polymerisation resins from acrolein, styrene, coumarone and indene. Styrene resins, which diminish a tendency to water absorption noticeable in vinyl resins, have been applied in making fountain-pen reservoirs. Coumarone and indene resins find their way into chewing gum and linoleum. Chlorinated diphenyl resins (aroclors) and toluene- $p$-sulphonamide resins, both possessing useful plasticising properties, were also mentioned.

\section{University and Educational Intelligence}

The firm of Messrs. W. H. Allen, Sons and Co., of Bedford, has long paid particular attention to engineering training. Mr. R. W. Allen, the present head of the firm, referred to this subject in his presidential address to Section G (Engineering) of the British Association. He pointed out that the engineering industry cannot be carried on efficiently without a continuous supply of highly-trained engineers and craftsmen, and it is necessary to provide workshop training for three main classes of students. First, there is the student who wishes to become a professional engineer, capable of taking highly responsible positions on the administrative, executive and technical side of the industry and for whom a university training is desirable, ensuring that thorough grounding in the fundamentals without which no engineer can be complete. Then there is the student who comes into the works direct from the public or secondary school, who may by enthusiasm and determination attain to the same positions as the university-trained man. Lastly, there is the training of craftsmen by apprenticeship, to whom, however, the way to higher positions must not be barred. The 'scholarship ladder' from the elementary school to the university must have its equivalent 'apprenticeship ladder' in the works ; it must be just as possible to-day as it was a century ago for a George Stephenson to begin at the bottom and achieve the heights. In every case, training should not be confined to the material and technical side, and although the passage of a student through the works may appear to be a severe and laboriously practical affair, it should at the same time engender a spirit very much akin to the public school spirit, which is essential to the formation of a true engineering character.

THE American University of Beirut, now in its sixty-seventh year, publishes in the current issue of its Bulletin of Information statistics of enrolments year by year from its foundation. These show that, excluding the preparatory school, there has been a continuous growth in numbers since 1920 from 381 to 1,004 . The last figure includes 538 in a faculty of arts and sciences, 126 in the school of medicine, 38, 68 and 17 respectively in schools of pharmacy, nursing and dentistry, 54 in an institute of music and 163 in a French school on the lines of the seven higher classes of a lycée. The University is a private, non-sectarian institution, no Government subsidies have ever been received, and there is no connexion between it and the Government of the United States. Character-training is one of its principal aims and religious exercises are a part of the daily routine.

IN "The New Home-making Education" (Bull. No. 3 of 1933, Washington, Government Printing Office, pp. 56, 10 cents) the United States Commissioner of Education presents a digest of a series of addresses which constitute an answer to the challenge of Aldous Huxley's "Brave New World". The forces which are making for the disintegration of home and family life are analysed, and brief accounts are given of the educational measures actually in operation or projected by which it is hoped not merely to salvage the home, but also to rehabilitate it as a permanent and fundamental element of American civilisation. Various aspects of the problem are first stated from the points of view of the Federal Office of Education, of superintendents of schools, and of college presidents. These statements are followed by papers by an economist, a sociologist, a historian and a home economist, and finally there are proposals by various eminent authorities on education. The notion that the family as an institution has reached a stage of obsolescence and is destined inevitably to give place to a different grouping is combated with the thesis that, on the contrary, it has now, thanks to the increased productivity of labour making it possible for the poorest parents to have ample leisure for attention to their children, an unprecedented opportunity for developing its latent possibilities of service to humanity. 